DOI: https://doi.org/10.32870/

\title{
El fin del poder
}

espiral.v21i60.295

Laura Loaeza Reyes`

El poder es cada vez más débil, más transitorio, más limitado es la tesis que sostiene el autor en este ensayo que desarrolla con base en la pregunta ¿de qué manera estas nuevas características del poder están configurando el mundo actual, tanto para los más poderosos como para la mayoría de la población?

El autor apoya sus tesis en numerosos ejemplos, mismos que documenta recurriendo a fuentes diversas: libros y artículos científicos, periódicos y revistas, estadísticas de fundaciones, organismos multilaterales, gobiernos de diversos países y entrevistas del autor con algunos mandatarios y exmandatarios de los países a los que alude.

Naím desarrolla su análisis con base en dos vectores. El primero es lo que caracteriza como tres grandes revoluciones: i) la revolución del más, referida al aumento de todo: niveles de vida, educación, salud, países, esperanza de vida, información, relaciones con otras personas, etc.; se trata de cambios cuantitativos pero también cualitativos que hacen que muchos de los factores que permitían ejercer el poder dejen de ser eficaces; ii) la revolución de la movilidad significa que todos estos cambios se expanden y circulan cada vez más; más gente, dinero, productos, tecnología, información, estilos de vida se mueven a menor

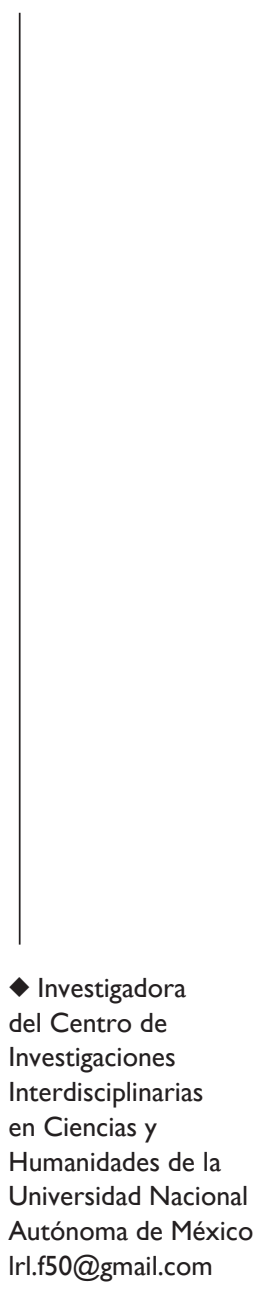
coste y a más lugares; los migrantes transfieren más Moisés Naím, 2014, El fin del poder, Random remesas a sus lugares de House Mondadori, México.

Espiral, Estudios sobre Estado y Sociedad

Vol. xxı No. 60 \ayo / Agosto de 2014 
origen, pero también transfieren ideas, aspiraciones, técnicas e incluso movimientos religiosos y políticos que minan el poder y el orden establecido en sus lugares de origen; el autor demuestra con cifras que las remesas son más importantes para esas economías que la inversión extranjera y que la ayuda económica de los países ricos (Naím, 2014: 98); iii) finalmente, la revolución de la mentalidad, referida a los grandes cambios en la forma de pensar, las expectativas y aspiraciones que acompañan a las transformaciones mencionadas; Naím denomina revolución de las expectativas crecientes a la distancia que existe entre lo que la gente espera y lo que sus gobiernos pueden darle, y es resultado de las revoluciones del más y de la movilidad.

El segundo vector del análisis es la fragmentación del poder que resulta en la confrontación entre los gobernantes o los grandes poderes tradicionales y los múltiples micropoderes. El autor representa la correlación de fuerzas entre ambos -o la impotencia de los primeros frente a estos últimos- con la imagen de Gulliver atado al suelo por miles de liliputenses que le impiden moverse. El poder de los micropoderes reside en su capacidad de vetar, contrarrestar, combatir y limitar el margen de maniobra de los grandes actores, y tienen la ventaja de que al ser más pequeños son más ágiles, además de que su estructura es menos rígida que la de los grandes poderes. Su estrategia es el desgaste, el sabotaje, el socavamiento y la obstaculización a los primeros. Cuando vemos el poder que tiene un solo hombre, como los informáticos Snowden o Hervé Falciani, para demostrar la vulnerabilidad de un servicio de seguridad nacional del país más poderoso del planeta, o bien para desvelar información confidencial del banco HSBC con la lista de 130 mil evasores fiscales de diferentes países, es difícil contestar esta tesis de Naím.

Pero el autor llama la atención sobre dos consecuencias negativas de esta nueva distribución del poder. Primera- 
mente, estos micropoderes están en manos de actores progresistas y bien intencionados que buscan el bien común, pero también de grupos criminales, fanáticos y extremistas que persiguen solo sus propios intereses. Aunado a ello, dado que todos tienen el poder suficiente para impedir las iniciativas de los demás, es difícil imponer una línea de actuación y en consecuencia las decisiones no se toman, se toman demasiado tarde o se diluyen resultando ineficaces (Naím, 2014: 41). Esto va en detrimento de la calidad de las políticas públicas y de la capacidad de los gobiernos para satisfacer las expectativas del electorado o resolver problemas urgentes.

Naím sitúa el inicio de estos cambios en la caída del Muro de Berlín y el surgimiento de Internet en 1990, pero enfatiza que estos eventos no fueron los únicos factores de cambio ni los más importantes en este sentido. Y con ello contradice una opinión muy difundida que atribuye estas transformaciones a las tecnologías de información y comunicación en sí mismas. En esto es muy enfático en diferentes secciones del libro. Naím sostienen que para que Internet pueda tener sus efectos sobre los procesos políticos y sociales se requieren otras condiciones que están relacionadas con las transformaciones demográficas y económicas, con los cambios políticos y con la ampliación de las expectativas, los valores y las normas sociales. En su opinión, las tecnologías de información y comunicación son solo herramientas que requieren de usuarios con objetivos, dirección y motivación. $\mathrm{Y}$ aunque reconoce que los ciberactivistas contribuyen a enriquecer el discurso político en todo el mundo y a cambiar la manera como se obtiene, se usa y se pierde ese poder, considera que es precisamente la difusión del poder la que les ofrece las oportunidades para conseguirlo. A fin de cuentas, los partidos políticos siguen siendo el principal vehículo para obtener el control del gobierno en una democracia. 
Entre los indicadores a los que el autor recurre para demostrar que cada vez más las minorías mandan -y de los cuales proporciona múltiples ejemplos siempre debidamente documentados-, destacan los siguientes. Cada vez menos gobiernos disfrutan de la mayoría en el Parlamento; en 2012, por ejemplo, solo cuatro de los treinta y cuatro países miembros de la OCDE gozaban de esta mayoría. Los jueces han adquirido una fuerza política que cada vez más contesta el poder del presidente y del Parlamento. En los conflictos armados los micropoderes desafían el poder de las fuerzas armadas, incluso las más grandes y costosas del mundo. Ejemplos de ello son el crimen organizado transnacional y los insurgentes talibanes que combaten con explosivos caseros, las milicias de las FARC colombianas, un comandante de Hamás o un bloguero yihadista con su ordenador que está haciendo "más con menos". Los cuerpos de seguridad y policías privados, en casos como el mexicano, estarían operando en esta misma línea. En ese sentido, la degradación del poder crea un terreno propicio para la proliferación de grupos criminales, terroristas y otros que atentan contra la seguridad ciudadana y en algunos casos, incluso, afectan la estabilidad internacional.

Estos cambios quedan contenidos en el concepto guerra de cuarta generación acuñado por los militares estadounidenses para referirse a "un conflicto caracterizado por el difuminado de los límites entre la guerra y la política, lo militar y lo civil. Es un conflicto en el que un actor no estatal violento lucha contra un Estado y en el que el enfrentamiento es militar, no solo en el estricto sentido de las hostilidades armadas, sino también porque se desarrolla entre los medios y la opinión pública, y porque cada bando se esfuerza tanto por socavar las bases y la legitimidad del otro como por derrotarlo en el campo de batalla. El terrorismo, la guerra cibernética y la propaganda son instrumentos habituales de la guerra de cuarta generación” (Naím, 2014: 179). 
De igual manera, prácticas antidemocráticas como el separatismo regional, la xenofobia, las campañas contra los inmigrantes y los fundamentalismos religiosos se benefician de la degradación del poder. Uno de los síntomas más evidentes y problemáticos de la degradación del poder es la capacidad de veto de los actores pequeños. Se trata de un recurso cada vez más socorrido tanto al interior de los países, en los parlamentos, como en la comunidad internacional. De acuerdo con Naím, la proliferación de organizaciones dedicadas a la cooperación internacional en numerosos temas permite a los países que cuentan con más organizaciones de este tipo ejercer un mayor poder de veto y no siempre en defensa de los principios universales. Al mismo tiempo, el aumento del poder de veto de los pequeños países obedece a que los países grandes ya no disponen de los mismos premios y represalias que tenían antes y que les permitía orientar el destino de los países pequeños; por ejemplo, "las donaciones privadas (personales y de instituciones) a países pobres ya alcanzan, y a veces superan, a las que hacen los gobiernos con las economías más grandes" (Naím, 2014: 302). Esta tendencia, sostiene, irá en aumento.

Pero esta fragmentación excesiva del poder y la incapacidad de los principales actores de ejercer el liderazgo son tan peligrosas como la concentración del poder en unas pocas manos. Además, dificulta los intentos de acción colectiva para resolver eficazmente problemas como la proliferación nuclear, el cambio climático o la inseguridad cibernética. En este contexto, afirma, surgen demagogos inexpertos y mal intencionados, a quienes denomina terribles simplificadores; sujetos que aprovechan la desilusión y la incertidumbre provocados por los cambios rápidos. La solución, sostiene, es muy difícil pero indispensable: dar más poder a quienes nos gobiernan, aunque no confiemos en ellos; para ello, los partidos políticos deberán adaptarse a las necesidades del siglo XXI. 
Observando dichos escenarios, sus conclusiones podrían resumirse de la siguiente manera: urge cambiar nuestra forma de pensar el poder para poder enfrentar una oleada de innovaciones que empezará desde abajo, será caótica y lenta pero inevitable. 